\title{
Adding time to the conservation toolkit: palaeoecology and long term wetland function dynamics
}

\author{
M. Jane Bunting $\cdot$ Nicki J. Whitehouse
}

Published online: 2 July 2008

(C) Springer Science+Business Media B.V. 2008

One of the many fascinating aspects of wetlands is their ability to preserve an archive of their own history in the accumulating body of sediments building up beneath the surface, particularly but not exclusively in peatlands. The sedimentary record can be thought of as an archive of monitoring data collected over centuries and millennia, waiting to be read. This special issue brings together a selection of papers presented at the 7th INTECOL Wetlands Meeting in Utrecht, The Netherlands, July 25th-30th 2004 (see also Verhoeven et al. 2006; Bobbink et al. 2006). These papers give a flavour of the wide range of methodologies used, and the situations investigated by palaeoecologists, and demonstrate how a palaeoecological perspective can add to our understanding of contemporary issues of concern such as fluctuations in biodiversity and the response of wetland systems to fluctuations in hydrology, water quality, and overall climatic change.

Palaeoecology, the study of this long-term record, takes a strongly interdisciplinary approach to reading this archive. The accumulating sediments within wetlands contain the remains of animals, plants and other organisms living in and around the wetland, as well as inorganic indicators of environmental processes such as soil erosion; a range of these proxies are represented in the papers in this special issue. Pollen and spores are produced by flowering plants and ferns across the landscape in very large amounts, and in many cases have evolved to be widely dispersed, though some distribute pollen more locally. Consequently, the distribution of plants and communities is hard to extract from the pollen record alone. Bunting (this issue pp. 000-000) explores some current work aimed at better interpreting the pollen signal from the archive. Transport to the wetland is less important when studying groups of organisms that only live in the wetland, such as testate amoeba (Mitchell et al. this issue pp. 000-000) or diatoms, or that are represented by larger, less widely dispersed

\footnotetext{
M. J. Bunting $(\bowtie)$

Department of Geography, University of Hull, Cottingham Road, Hull HU6 7RX, UK

e-mail: m.j.bunting@hull.ac.uk

N. J. Whitehouse

School of Geography, Archaeology and Palaeoecology, Queen's University Belfast,

Belfast BT7 1NN, UK

e-mail: n.whitehouse@qub.ac.uk
} 
fragments such as plant macrofossils (Mauquoy and Yelov this issue pp. 000-000; Ayres et al. this issue pp. 000-000), Coleoptera (beetles) and Chironomidae (non-biting midges) (Whitehouse et al. this issue pp. 000-000), Mollusca (Ayres et al. this issue pp. 000-000), and all reflect slightly different aspects of the past environment. The structure of the peat itself and its landscape setting also provide information on past, present and future wetland dynamics (Tipping this issue pp. 000-000). Establishing when things happened is an important palaeoecological tool, and chronologies can be established using methods such as radiocarbon dating (Mauquoy and Yelov this issue pp. 000-000; Tipping this issue pp. 000-000), short-lived isotope dating methods (Ayres et al. this issue pp. 000-000) or other markers such as spheroidal carbonaceous particles (Whitehouse et al. this issue pp. 000-000).

Using these methods, palaeoecologists explore the formation, development and dynamics of biological communities over long temporal periods, and reconstruct the impact of environmental change and human activity both in the wetlands themselves and in the surrounding terrestrial ecosystems. Wetlands also contain evidence of their cultural significance to past human societies, through archaeological artefacts such as bog bodies and votive offerings, and of the use of wetland resources by humans through artefacts such as trackways and fishing and hunting equipment. The palaeoecological record indicates that human impact on the wetland landscape has increased over the last 10,000 years, with periods of abrupt, dramatic change punctuated by episodes of relative stability, against a backdrop of climate oscillations. Palaeoecology is also a means to learn more about how landscapes and ecosystems have responded to environmental change, whether climate or human-induced, and thus better predict how they might respond to current and future perturbations, a key concern in the current context of global warming.

Wetlands provide important ecosystem services for society (including flood risk amelioration and carbon storage) and support biodiverse, habitat-specific ecosystems. However, they are also continually under threat from human activity; pollution, exploitation of wetland resources and deliberate or unintentional drainage have damaged or destroyed many wetlands, removing not just the surface functions but also the archive of the development of both the wetland and its surroundings. Around 62\% of European mires and peatlands are estimated to have been destroyed by human activity (Joosten 1999), and most surviving wetland systems require active management and/or restoration work to bring them back to a sustainable state of ecosystem health.

Effective conservation requires both a detailed knowledge of the ecology of the biota concerned including the development of habitats and ecosystems through time, and how species have responded to environmental and anthropogenic changes. Palaeoecological investigations can reconstruct unique site histories, test alternative hypotheses explaining the current state of a system, support predictions about the response of the system to future changes and contribute to our understanding of key ecological issues such as colonisation rates for new wetland areas and the dynamics of biodiversity in response to system changes. Therefore we argue that palaeoecology needs to be in the toolbox of any project working to understand, defend, conserve, manage or reconstruct wetland systems.

When planning the management of a wetland system, there will sometimes be disagreement as to what constitutes appropriate management, how to set appropriate restoration goals or indeed what is the "natural" state of a wetland at the site or in the region, and palaeoecology can provide a useful new perspective for these debates. We know, for instance, that the longer palaeoecological picture is one of change and not of stability. For example, woodlands are found to have repeatedly expanded onto peat surfaces during earlier stages of mire development (Chambers 1996; Whitehouse in review). In some cases, these woodlands developed from fen woodland occupying the site before the switch to mire 
development occurred, but distinctive wooded bog and bog woodland communities also occur, often dominated by pine (MacKenzie and Worrell 1995; McHaffie et al. 2003). Many bog woodlands persisted over millennia, contracting during wetter periods and re-expanding during periods of surface dryness (Boswijk and Whitehouse 2002). Taking a palaeoecological perspective it is quite clear that these bog woodlands are part of the raised mire ecosystem and that they play an important biodiversity role on sites (Chambers 1996; McHaffie et al. 2003). Yet today, trees colonising the mire surface are generally treated as undesirable invaders. They are removed (sometimes with the use of chemicals) in an attempt to maintain a high water table and retain sites in an idealised treeless state. Perhaps the removal of trees is justifiable in some situations, but the palaeoecological perspective suggests that this is not universally the case.

The papers in this special issue illustrate other ways in which a palaeoecological perspective can contribute to understanding of wetland ecosystems and therefore to informed decision making about their conservation. Whitehouse et al. (this issue pp. 000-000) compare patterns of biodiversity within two different systems, Coleoptera in raised mires and Chironomidae in ponds, demonstrating the different time scales of change in biodiversity, and emphasising the importance of the longer-term perspective as a tool for understanding the value of the existing site and what might happen in response to management and restoration activities.

All the papers show the dynamic and complex nature of wetland response to climate change and human activity when viewed from a palaeoecological perspective. Mitchell et al. (this issue pp. 000-000) review testate amoebae analysis, a relatively new technique which is allowing reconstruction of surface moisture levels in bogs, and can also be used to monitor the effectiveness of restoration schemes. Bunting (this issue pp. 000-000) uses pollen analysis to reconstruct the dynamics of a Canadian wetland over the last millennium, showing the importance of the wetland response to early nineteenth century European settlement for explaining the present-day wetland communities. Chambers et al. (2007) also report an example of historical processes disrupting apparently stable ecosystem dynamics, showing that the industrial revolution appears to have had a serious effect on reducing the floral diversity and changing the community structures of blanket mires in the Cambrian Mountains, Wales. Ayers et al. (this issue pp. 000-000) focus on the last 150 years, using multi-proxy techniques to explore the recent history of a community of rare Najas marina in a Norfolk (UK) lake and develop an informed management proposal, whilst Whitehouse et al. (this issue pp. 000-000) give examples showing the impact of eutrophication on shallow pond ecosystems over similar timescales. Tipping (this issue pp. 000-000) pulls together multi-proxy data from a range of sites to critically review some commonly made assumptions about blanket peat dynamics, arguing that human impact is actually much less significant in Scottish systems than has been argued for England and Wales (e.g. Moore 1993). Mauquoy and Yelov (this issue pp. 000-000) illustrate how an understanding of past bog dynamics and responses can be used to predict the consequences of future climate change, highlighting the potentially severe and immediate threat to Sphagnum-dominated wetlands.

Conservation and restoration decisions raise long-term questions which deserve considered debate. Do we accept that ecosystems are constantly evolving and therefore expect sites to change, even under conservation-directed management? Do we plan to manage in such a way as to disrupt succession and enable 'desirable' seral stages (for example, reedbeds) to persist in the face of natural processes? How do we define benchmarks and targets: are we aiming to recreate the wetland of 10-20 years ago or of several hundred years or even thousands of years ago? The palaeoecological record contributes to these debates, but also shows how much we have to learn about ecosystem processes. The record tells us that 
change is the natural state of ecosystems; perhaps we need to be more accepting of change, using the long term record to help us identify what the likely outcomes of current processes are and what we might be able to do to deflect or hasten those trajectories rather than using it as a tool to look backwards and set inappropriate benchmarks based on environmental conditions that no longer pertain. 'Restoration' is an important theme in conservation practice at present, but this can give the false impression that any site is replaceable. If an ecosystem can be recreated elsewhere, or damage can be repaired, then arguments for the conservation of particular sites is weakened. The palaeoecological perspective emphasises that no two sites are identical; each is characterised by a particular suite of species, each formed in response to unique historical and environmental parameters.

The papers in this special issue give a flavour of the range of methods available in palaeoecology and the variety of questions they can address, from the rate of development of endemic populations of Coleoptera (Whitehouse et al. this issue pp. 000-000) to informing site-specific management decisions (Ayers et al. this issue pp. 000-000). Palaeoecological investigations can enrich a variety of debates which are generally seen as the province of ecology, biological conservation, or restoration ecology, but they are not widely employed. The data available are not collected at comparable spatial, temporal and taxonomic resolutions to data collected through conventional site visits and monitoring, and therefore cannot be seamlessly incorporated into an ecological argument. However, with good communication between practitioners in different fields, the unique perspective provided by palaeoecology can make a substantial contribution to understanding present-day biodiversity and system function, and to the development of effective conservation management practices for systems, especially given the anticipated challenges of $21^{\text {st }}$ century environmental change.

\section{References}

Bobbink R, Beltman B, Verhoeven JTA, Whigham DF (eds) (2006) Wetlands: functioning, biodiversity, conservation and restoration. Series: ecological studies 191, Springer, Berlin, p 315

Boswijk G, Whitehouse NJ (2002) Pinus and Prostomis: a dendrochronological and palaeoentomological study of a study of a mid-Holocene woodland in Eastern England. Holocene 12(5):585-596

Chambers FM (1996) Bogs as treeless wastes: the myth and the implications for conservation. In: Parkyn L, Stoneman R, Ingram H (eds) Conserving peatlands. CAB International, Wallingford, UK, pp 108-175

Chambers FM, Mauquoy D, Cloutman EW, Daniell JRG, Jones PS (2007) Recent vegetation history of Drygarn Fawr (Elenydd SSSI), Cambrian Mountains, Wales: implications for conservation management of degraded blanket mires. Biodivers Conserv 16:2821-2846

Joosten JHJ (1999) Peat the final frontier: Mires and peatlands outside the tropics. In: Maltby E, Maclean L (eds) Peatlands under pressure. Arctic to tropical peatlands. Royal Holloway Institute for Environmental Research, Royal Holloway, UK, pp 9-17

MacKenzie NA, Worrell R (1995) A preliminary assessment of the ecology and status of ombrotrophic wooded bogs in Scotland. [SNH Research, Survey and Monitoring Report no.40], Scottish Natural Heritage, Battleby

McHaffie H, Legg CJ, Worrell R, Amphlett A (2003) Scots pine growing on forested mires in Abernethy Forest, Strathspey. Bot J Scot 54:209-219

Moore PD (1993) The origin of blanket mire, revisited. In: Chambers FM (ed) Climate change and human impact of the landscape. Chapman and Hall, London, pp 217-224

Verhoeven JTA, Beltman B, Bobbink R, Whigham DF (eds) (2006) Wetlands and natural resource management. Ecological studies 190, Springer, Berlin, p 347

Whitehouse NJ (in review) Biodiversity, restoration, and re-gardening in "natural" and "cultural" landscapes; lessons from Quaternary entomology. In: Hall M (ed) Restoria, Routledge, UK 